\title{
Resignation ist keine Option
}

«DOK»: Der Arzt im Rollstuhl

Donnerstag,

4. September, 20.05 Uhr

Schweizer Fernsehen SF1
Wacher Blick, schnelle, zielstrebige Bewegungen, selbstbewusstes Auftreten: Der junge Mann, den Claudia Heim in ihrem DOK-Film porträtiert, strahlt eine eindrückliche Präsenz aus. Christian Wenk darf in verschiedener Hinsicht als privilegiert bezeichnet werden: Beruflich als Assistenzarzt Medizin im Kantonsspital Luzern und angehender Oberarzt in Nottwil auf Kurs, privat glücklich in der Beziehung mit Freundin Jacqueline, sportlich engagiert als Cheftrainer des Handbike-Nationalteams, das musikalische Talent als erfolgreicher Pianist auslebend.

Ein Lebensentwurf, den sich manch einer wünschen würde und dessen Eckpunkte sich schon im Herbst des Jahres 2000 vergleichbar präsentierten. $\mathrm{Zu}$ dieser Zeit noch Medizinstudent, mischte Christian Wenk im Duathlon, der wettkampfmässig betriebenen Kombination der Disziplinen Laufen und Radfahren, an der Weltspitze mit.

Doch die Aussagekraft solch äusserer Vergleiche ist beschränkt. Denn allen Parallelen zum Trotz liegen zwischen damals und heute Welten. Im September 2000 erlitt der junge Athlet bei einer Trainingsfahrt in Japan einen schweren Unfall, als er mit seinem Rad am Ausgang einer unübersichtlichen Kurve in hohem Tempo gegen ein Auto prallte, das dort am Strassenrand abgestellt war. Seither ist Christian Wenk querschnittgelähmt.

Was mag in einem Menschen vorgehen, einem energiegeladenen Bewegungstypen zumal, wenn er gewissermassen von einer Sekunde auf die andere mit der Tatsache konfrontiert ist, dass sich sein Leben in einschneidendster Weise verändert hat, dass vieles, was für ihn bis anhin Motivation und Lebensfreude bedeutete, nicht mehr möglich sein wird? Wie würde man selbst

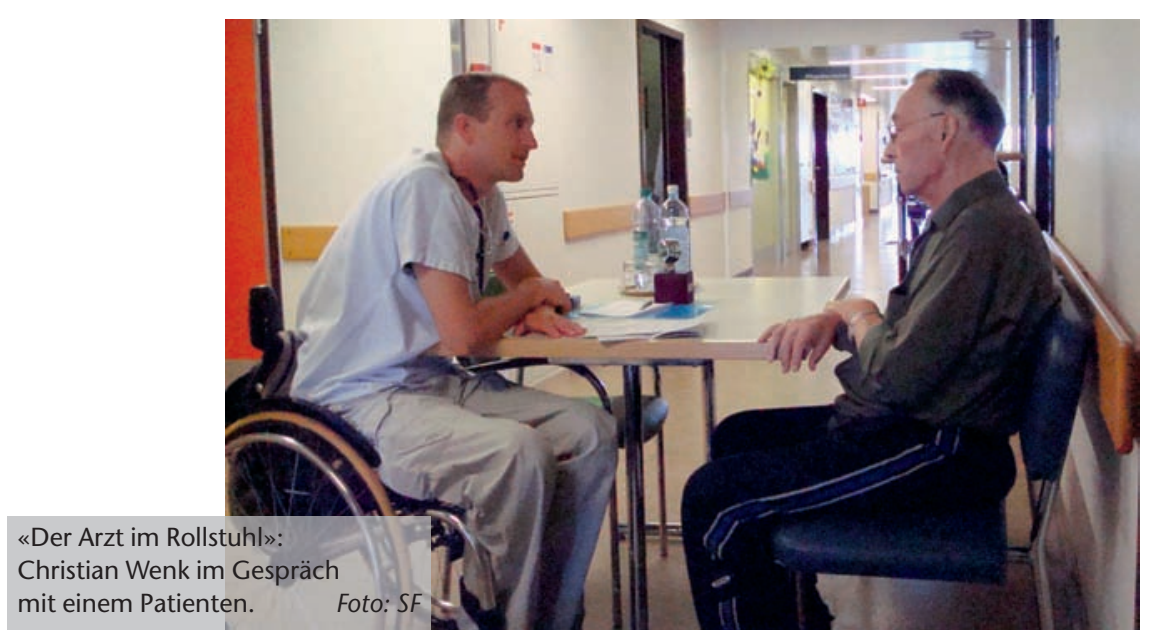

in einer vergleichbaren Situation - vor der ja niemand gefeit ist - reagieren? Gedanken, die sich beim Erleben des Films «Der Arzt im Rollstuhl» fast zwangsläufig einstellen.

Während der Film auf die zweite Frage naturgemäss keine Antwort geben kann, erschliessen sich dem Zuschauer im Verlauf des 50-minütigen Porträts zumindest Teile der Innenwelt des Protagonisten. Ohne aufdringlich-voyeuristisch zu wirken, nähert die Dokumentarfilmerin sich Christian Wenk mit einer Unbefangenheit, die etwas Befreiendes hat, vielleicht auch für den Porträtierten selbst hatte. Jedenfalls gibt er in natürlich-offener Art auch auf persönliche, mitunter intime Fragen ebenso aufschlussreiche wie überzeugende Antworten - seine berufliche Erfahrung dürfte ihm dabei zugutegekommen sein.

Das Bild der Persönlichkeit Christian Wenk, des «Arztes im Rollstuhl», das der Film vermittelt, ergibt sich indes nicht nur aus den Interviewsequenzen - dies würde dem gewählten Medium auch nicht gerecht. Das DOK-Team begleitete die Handbike-Nationalmannschaft - die querschnittgelähmten Teammitglieder bedienen ihre Spezialräder ausschliesslich mit den oberen Extremitäten - und ihren Cheftrainer nach Sardinien in ein Trainingslager. Christian Wenk offenbart dabei Eigenschaften, die es ihm nach dem Unfall wohl ermöglicht haben, seinen Weg trotz Krisen und Rückschlägen erstaunlich «bruchlos» fortzusetzen, aber auch solche, die ihm dabei vielleicht etwas in die Quere kamen. Grundsätzlich wird Schwierigkeiten aber mit scheinbar unerschütterlichem Optimismus begegnet - Resignation scheint für ihn keine Option zu sein.

Der filmische rote Faden der Sardinienreise wird unterbrochen durch Szenen aus dem beruflichen und privaten Alltag des Porträtierten, durch Aussagen von Eltern, Freundin, Kollegen und Vorgesetzen. Eine Aussenperspektive, die nicht nur spannende Facetten der Person Christian Wenk ergänzt und somit das Bild abrundet, sondern auch Einblick in die Umstände gibt, mit denen die Angehörigen von Paraplegikern konfrontiert sind. Beeindruckend und erstaunlich um diese Begriffe kommt man beim Phänomen Christian Wenk nicht herum - bleibt, wie ausgeprägt sich bei ihm und seinem engsten Umfeld eine «neue Normalität» eingespielt hat. Seine Freundin jedenfalls wirkt zunächst fast etwas ratlos, als sie gefragt wird, was denn bei ihnen infolge der Behinderung ihres Partners anders sei als bei andern Paaren. «Eigentlich nichts», ist ihre erste, spontane Antwort.

Bruno Kesseli 